\title{
A SEXUALIDADE FEMININA NO BRASIL: CONTROLE DO CORPO, VERGONHA E MÁ-REPUTAÇÃO
}

\author{
FEMALE SEXUALITY IN BRAZIL: BODY CONTROL, SHAME, AND BAD \\ REPUTATION
}

Lorena de Oliveira*

RESUMO: O trabalho investigou como a sexualidade feminina no Brasil é considerada um objeto de vergonha e uma má-reputação. Utilizou referenciais teóricos preocupados em analisar as formas de controle da sexualidade de mulheres na história. Investigou também como a sociedade atual reflete este controle por meio de comportamentos machistas, focando na análise de denúncias de crimes sexuais cometidos contra mulheres no Brasil. Em ambas as análises, o estudo destacou formas de controle do corpo feminino e reprodução de papéis de gênero, em que o masculino deve ser livre e o feminino controlado. Assim, a mulher que não se submete aos regramentos morais que a sociedade impõe sobre sua sexualidade é marcada por uma má-reputação e responsabilizada pelas violações sofridas.

PALAVRAS-CHAVE: Corpo; feminismo; interseccionalidade; sexualidade.

ABSTRACT: The study investigates how female sexuality in Brazil is considered an object of shame and a bad reputation. Used theoretical references concerned with analyzing the first forms of control of women's sexuality in history. Also, investigated how actual society reflects this control through machist behavior, focusing on the analysis of complaints of sexual crimes committed against women in Brazil. In both analyzes, the study observed forms of control over the female body e reproduction of gender roles, in which the male must be free and the female controlled. Thus, the woman who doesn't submit herself to the moral rules that society imposes on sexuality is marked by a "bad reputation" and held responsible for the violations suffered.

KEY-WORDS: Body; feminism; intersectionality; sexuality.

\section{INTRODUÇÃO}

Durante a evolução histórica da humanidade é possível perceber que aspectos subjetivos dos indivíduos passam a integrar estruturas de poder nas sociedades. Entre estes aspectos, a sexualidade também é refletida, seja pela sua limitação ou pela sua liberdade. Uma análise histórica sobre o tema reflete que a maior ou menor liberdade sexual dos sujeitos pode estar relacionada tanto pelos usos e costumes dos grupos

\footnotetext{
* Graduada em Direito e Mestranda em Direitos Humanos pela Universidade Federal de Goiás (UFG). Especialista em Ciências Criminais pela Pontifícia Universidade Católica de Goiás (PUC-GO). Membro do Grupo de Estudos e Pesquisas Dialogus - Estudos Interdisciplinares em Gênero, Trabalho e Cultura, da Universidade Federal de Catalão (UFCAT) e Direito e Sexualidade da Universidade Federal da Bahia (UFBA).
} 
sociais, quanto pelos interesses do Estado. Entre as principais formas de monitoração da sexualidade pelos governos e dentre variados fatores, há preponderância daqueles relacionados ao controle dos corpos.

Neste controle, fatores interseccionais se relacionam diretamente na forma como os corpos dos sujeitos são considerados no ambiente social, entre os quais não se pode deixar de destacar o gênero. Isso porque, historicamente, os corpos femininos foram alvos de controle e moralidades que não foram percebidas de igual forma nos corpos masculinos, fato que evidencia a reprodução de papéis de gênero, principalmente na dicotomia entre masculino (livre) e feminino (controlado).

Este fator se perpetuou na evolução histórica da sociedade, porém sendo percebido de diferentes formas. Neste sentido, vê-se ainda hoje no Brasil claras limitações ao corpo feminino, como por exemplo na criminalização do aborto, pois, apesar das ferrenhas bandeiras como uma defesa do direito à vida, é, antes de tudo, uma clara restrição imposta ao corpo feminino e uma questão de saúde pública. De igual forma, casos de crimes sexuais cometidos contra mulheres evidenciam uma opinião pública majoritária de que as vítimas é que devem ser responsáveis por protegerem os seus corpos e que a vida sexual - pregressa - da mulher é um fator determinante para que o crime sexual seja ou não imputado ao agente. Logo, a análise destes delitos, numa sociedade machista e sexista como o Brasil, preocupa-se mais com o comportamento da própria vítima do que com as ações ilícitas do criminoso.

Este fator gera um processo de culpabilização das vítimas, o qual acarreta em todas as mulheres variados sentimentos, entre os quais se destaca a vergonha e a descrença em instituições, já que estas refletem em seus procedimentos os mesmos preceitos machistas e sexistas da opinião pública majoritária. Assim, entende-se que o exercício da sexualidade por mulheres é considerado uma má-reputação, a qual acarretará à mulher a responsabilidade por ter sido vítima de crimes de cunho sexual.

Diante destes fatores, compreende-se que a mulher que exerce livremente sua sexualidade no Brasil está sujeita a ser duplamente julgada: ora pela sociedade, ora pelas instituições. Por este motivo, a sexualidade feminina no Brasil atual passa a ser considerada um fator de descrédito às próprias mulheres, pois no meio social está fadada a julgamentos pautados em moralidades e machismos e, nas instituições, caso 
seja vítima de crimes sexuais, sua vida sexual será fator determinante para a forma com que o sistema de justiça irá lidar com seu caso.

Com isso é possível questionar: Como a sexualidade feminina foi lida historicamente? Como é lida no Brasil atual? A forma como a mulher brasileira exerce sua sexualidade é um fator determinante nas investigações de crimes sexuais no Brasil? Estas são as respostas que o presente trabalho buscou encontrar. Como metodologia foi utilizada a revisão bibliográfica de estudos sobre o corpo feminino e controle sexual de mulheres, principalmente pela análise histórica presente em Calibã e a Bruxa, de Silvia Federici (2017), e dados estatísticos referentes a denúncias de crimes sexuais registradas no Brasil nos últimos anos.

\section{A CONSTRUÇÃO DA SEXUALIDADE FEMININA COMO UMA QUESTÃO DE ESTADO DURANTE A CAÇA ÀS BRUXAS}

Ao se falar sobre sexualidade feminina por meio de uma análise histórica mostra-se necessário indicar o recorte estudado, devido à abrangência do tema e à impossibilidade de esgotá-lo em um só estudo. Com isso, o presente trabalho traz como foco de análise o controle exercido pela Igreja Católica no contexto da Europa Medieval, já que se preocupou em "regular o comportamento sexual" (FEDERICI, 2017, p. 80). Para atingir este objetivo, a Igreja Católica utilizou principalmente dois instrumentos: os "penitenciais" e a atribuição de um novo significado à sexualidade, a qual foi vinculada à intimidade e vergonha.

O primeiro instrumento refere-se a verdadeiros manuais práticos utilizados para o controle das práticas sexuais da população. Entre as principais características destes manuais, destacam-se "detalhadamente as posições permitidas durante o ato sexual [...], os dias em que se podia fazer sexo, com quem era permitido e com quem era proibido" (FEDERICI, 2017, p. 81). A relevância destes manuais também foi evidenciada por Foucault (História da Sexualidade, 1978), que destacou como foram essenciais para a produção do sexo como um discurso. Esse controle sexual posteriormente resultará, entre outros fatores, na declaração do casamento como um sacramento que não pode ser desfeito e também na repressão à homossexualidade, 
por meio dos Concílios de Latrão. Com isso, vê-se que neste período a sexualidade foi lida pelo Estado e pela Igreja Católica (e, consequentemente, pelos indivíduos) como um discurso vinculado à religião e revestido de extrema intimidade. Nesse sentido, a partir do trabalho de Mary Condren (1989), Federici destaca que a sexualidade neste período

Transformou-se num tema de confissão, no qual os mais íntimos detalhes das funções corporais mais íntimas se transformaram em tema de discussão [...] os diferentes aspectos do sexo foram divididos no pensamento, na palavra, na intenção, nas vontades involuntárias e nos fatos reais do sexo para conformar uma ciência da sexualidade. (FEDERICI, 2017, p. 80)

Dessa forma, a sexualidade deixa de ser lida como algo próprio do sujeito e passa a ser encarada como uma questão de Estado, o qual passou a controlá-lo por meio dos ensinamentos católicos, principalmente pelo instituto do casamento. Porém, as limitações foram impostas de diferentes formas para homens e mulheres: se para eles a preocupação referia-se ao sagrado e às penitências, para elas foram atribuídas à vergonha, sendo este o segundo ponto que é destacado no processo de regulação do comportamento sexual nessa fase histórica.

A forma como a sexualidade feminina foi controlada/reprimida neste período deu-se tanto na esfera social quanto pelas instituições. Como destacado em Calibã e a Bruxa (FEDERICI, 2017), as mulheres foram expulsas dos momentos de liturgia e dos sacramentos, excluindo-as de um dos principais eixos da vida europeia medieval, a Igreja. Ainda, no campo social, o sagrado para os homens foi relacionado à distância entre mulheres e o sexo, sendo este um dos fatores que trará as penitências como um forte costume da época e, de uma forma mais complexa, o celibato clerical. Porém, atendendo ao recorte teórico que o estudo propõe, há um maior destaque na abordagem referente às significações que foram imputadas às práticas sexuais, principalmente no que se refere às mulheres.

Neste sentido, destaca-se que a diferente forma de controle que foi imposta às mulheres não se deu sem um motivo determinante. O Estado e a Igreja Católica do período impuseram estas medidas por entenderem que o desejo sexual conferia às 
mulheres um certo poder em relação aos homens. Tal poder representava uma forte ameaça ao Estado, pois, além de as mulheres estarem excluídas do jogo político e das relações de poder no período medieval, a forma com que exerciam sua sexualidade refletia diretamente nas questões reprodutivas. Logo, o Estado preocupou em controlar a sexualidade feminina, porém impondo a esta um diferente significado, com o intuito de "fazer da sexualidade um objeto de vergonha" e "uma questão de Estado" (FEDERICI, 2017, p. 80-82). Assim, entende-se que se a sexualidade para o homem era tida como um ato permitido, porém revestido de cautela, para as mulheres era sinônimo de vergonha e que somente deveria ser praticado para fins reprodutivos, jamais para o prazer.

Ainda, há uma intrínseca relação entre a sexualidade feminina e as questões reprodutivas. Destaca-se que o pensamento predominante no período histórico de análise, de uma forma simplista, era que quanto maior uma população fosse, mais mão-de-obra disponível o Estado teria para se enriquecer. Por este motivo, não era interessante para o Estado que mulheres controlassem o aumento de suas famílias, pois essa decisão refletia diretamente na taxa de natalidade da população.

Deste modo, mulheres passaram a ser condenadas por "crimes reprodutivos", os quais estiveram bastantes presentes na caça às bruxas. Este movimento foi instaurado na Europa Medieval, dentre outros fatores, como uma forma de disciplinar mulheres por diversos comportamentos considerados como "bruxarias", os quais estavam indiretamente relacionados com interesses políticos. No que se refere aos crimes reprodutivos, por exemplo, as mulheres - bruxas - passaram a ser condenadas pela diminuição da população, um fato que contrariava os interesses econômicos do Estado. Por este motivo,

As bruxas, segundo se sustenta, eram acusadas pelo fato de que morriam muitas crianças, porque elas morriam subitamente, morriam pouco depois de nascer ou porque eram vulneráveis a uma grande gama de enfermidades [...] as mulheres que eram chamadas de bruxas também eram acusadas de impedir a concepção. (FEDERICI, 2017, p. 326) 
Com isso, é possível compreender que, neste período, a criminalização do controle de natalidade por parte das mulheres e o controle de seus corpos foi uma resposta direta aos interesses econômicos do Estado, o qual, para atingir seus objetivos, defendeu o movimento de caça às bruxas com a Igreja Católica. Assim, observa-se um reflexo deste movimento na crítica inicial exposta neste estudo sobre o direito ao aborto. Hoje em dia depreende-se que o discurso em defesa da vida tem grande apoio dos segmentos religiosos e despreza argumentos que reivindicam a liberdade da mulher em decidir sobre seu próprio corpo. Não seria também essa uma forma de controlar o corpo feminino na atualidade por meio de uma caça às bruxas? Como não se trata da matéria central em discussão, tal questionamento não será aprofundado, mas destaca-se a necessidade de compreender como essas restrições históricas ainda são verificadas na sociedade atual, mesmo que com outra roupagem.

Neste processo de caça às bruxas na Europa Medieval ainda é essencial destacar que

a bruxa não era só a parteira, a mulher que evitava a maternidade ou a mendiga que, a duras penas, ganhava a vida roubando um pouco de lenha ou de manteiga de seus vizinhos. Também era a mulher libertina e promíscua - a prostituta ou a adúltera e, em geral, a mulher que praticava sua sexualidade fora dos vínculos do casamento e da procriação. (FEDERICI, 2017, p. 331-332)

Deste modo, observa-se que se mesmo a mulher submetida ao casamento dentro dos preceitos religiosos que eram dela esperados estava sujeita a ser acusada de bruxaria, a mulher que optava por viver livremente certamente também seria condenada por sua escolha. Com isso, ao ser julgada, “a 'má-reputação' era prova de culpa" (FEDERICI, 2017, p. 332). Tal fato era tão enraizado nestes julgamentos que era comum que se investigasse se as mulheres eram virgens ou não, já que a virgindade poderia ser considerada uma prova de sua inocência. Tal fato também se relaciona com a vergonha que era atribuída à sexualidade feminina, pois o discurso religioso, ao mesmo tempo em que fez com que as mulheres e o sexo fossem considerados algo a ser evitado, fez com que a sexualidade também se tornasse algo a ser escondido e protegido pelas próprias mulheres, já que poderia ser condenada 
caso a exercesse livremente e também devido ao fato de a virgindade ser considerada algo sagrado. Esses fatores ocasionaram à mulher o duplo julgamento: social e institucional. Isso acarretava em verdadeira descrença com as instituições e formas com que os julgamentos eram conduzidos, já que a condenação era praticamente certa, pois, como declarado por Jean Bodin: "devemos disseminar o terror entre algumas, castigando muitas" (FEDERICI, 2017, p. 333). A lógica de gerar o terror por meio do castigo foi bastante exitosa aos interesses do Estado e Igreja Católica, pois

podemos imaginar o efeito que teve nas mulheres o fato de ver suas vizinhas, suas amigas e suas parentes ardendo na fogueira, enquanto percebiam que qualquer iniciativa contraceptiva de sua parte poderia ser interpretada como produto de uma perversão demoníaca. (FEDERICl, 2017, p. 330)

Assim, os objetivos foram por eles alcançados, pois ao mesmo tempo em que o medo de ser condenada se espalhava entre as mulheres, as iniciativas contraceptivas passaram a ser evitadas ao máximo, já que poderiam lhe resultar em acusações de bruxaria. Com isso, o medo de tais julgamentos acaba por estimular a reprodução de mulheres, para que fossem afastadas da responsabilização pela diminuição da natalidade e, ainda, estimuladas a se casarem, evitando que fossem julgadas como "libertinas" ou "promíscuas".

Por todos esses fatores aqui apontados entende-se que o controle do corpo feminino exercido por meio da caça às bruxas foi determinante para que a sexualidade de mulheres, ao longo da história, fosse lida como algo vergonhoso e a ser escondido e, sobretudo, considerada uma questão de Estado. Infelizmente, esse fator ainda se repete no momento histórico atual, principalmente pelo fato de que mulheres que exercem livremente sua sexualidade sofrem com o mesmo julgamento de ter uma máreputação. Ainda, este fator também é utilizado como fundamento para a responsabilização de mulheres vítimas de crimes sexuais, assim como foi utilizado para que fossem queimadas nas fogueiras anos atrás.

Neste sentido, será demonstrado na próxima seção como os papéis de gênero são refletidos na sociedade como fatores delimitadores da sexualidade feminina, 
destacando as construções de poder envoltas nos paradoxos entre masculino e feminino.

\section{A VIOLÊNCIA DE GÊNERO NA SEXUALIDADE FEMININA E O CONTROLE DO CORPO}

A análise de crimes sexuais cometidos contra mulheres no Brasil frequentemente aponta dados semelhantes no decorrer dos anos. Por exemplo, é sabido que a maioria das agressões ocorre na própria casa da vítima e que os principais agressores são pessoas próximas, amigos, familiares, companheiros, etc ${ }^{1}$. Estes dados destacam que a violência contra a mulher, aqui focando no cometimento de crimes sexuais, é perpetuada por certa naturalização da sociedade e pensamento de que a mulher é a culpada pela violação sofrida, retirando toda a responsabilidade do agressor. Neste sentido, a pesquisa "Tolerância social à violência contra as mulheres", realizada pelo Ipea (Instituto de Pesquisa Aplicada) e divulgada em 2014 também evidenciou este fato. Ao questionar os entrevistados "se as mulheres soubessem como se comportar haveria menos estupros", 58,5\% dos entrevistados concordaram.

Esses dados são bastante preocupantes, pois há uma transferência da responsabilidade do delito, em que as próprias vítimas passam a ser responsabilizadas. Não há dúvidas de que tal pensamento majoritário tem como base preceitos machistas e sexistas que estão enraizados na sociedade brasileira desde sua origem. No entanto, esse fator também escancara uma diferença em relação aos corpos dos sujeitos no ambiente social: o corpo masculino é livre e o feminino é (e deve ser) controlado/escondido; sendo esta uma percepção baseada em questões de gênero. Importante destacar que o conceito de gênero aqui utilizado aproxima-se da perspectiva apresentada por Joan Scott, referindo-se a "um elemento constitutivo de relações sociais baseadas nas diferenças percebidas entre os sexos" e "uma forma

\footnotetext{
1 Todas as pesquisas consultadas indicaram essa resposta ao questionar aos entrevistados sobre os agressores e o principal local de agressão, vide: A violência contra a mulher (IPEA, 2016, p. 15-16) e Percepções e comportamentos sobre violência sexual no Brasil (INSTITUTO, 2016, p. 5, 26-27);
} 
primária de dar significado às relações de poder" (SCOTT, 1995, p. 86). Logo, as relações de poder existentes entre homens e mulheres necessariamente se vinculam à construção social que os diferenciam a partir de papéis que são deles esperados, como a virilidade/masculinidade, delicadeza/feminilidade, dentre tantos outros, até alcançar a já conhecida dicotomia público/masculino e privado/feminino. No entanto, da análise dos comportamentos que a sociedade espera de homens e mulheres, quando relacionados aos crimes sexuais, há uma inversão nesse processo: o corpo feminino passa a ser público, não por ser livre e transitar sem amarras no ambiente social, mas sim pelo contrário, por estar sujeito a violações por quem entender ser seu "direito", sendo que o grupo hegemônico que mais se apropria desse discurso são os homens.

A naturalização desse pensamento acarreta em outro ainda mais gravoso, o qual sustenta uma visão de que o homem possui mais virilidade e por isso necessita suprir sua necessidade sexual a todo custo, mesmo que para isso tenha que violar corpos alheios. Esse pensamento imputa às mulheres o dever constante de vigilância, pois se não se proteger estará sujeita e até mesmo motivando violações, já que não se comportou ou não se vestiu da maneira que a sociedade julga ser correta. Desta forma, há no ambiente social a predominância de um discurso machista, no qual se questiona: por que proteger a mulher, se nem ela mesma se protege? Essa ideia se relaciona à forma com que o corpo feminino é visto: como algo a ser protegido a todo custo e, consequentemente, controlado. Com isso, as atitudes, vestimentas e comportamentos femininos passam a ser condicionados ao que a sociedade espera da imagem de mulher construída pelos papéis de gênero e, ao mesmo tempo, marginaliza aquelas que são consideradas vulgares, libertinas, vadias, livres. Desta forma, uma vez se afastando do que lhe é esperado, a mulher passa a ser a responsável por qualquer violência que possa ser por ela sofrida.

Consequentemente e, já sendo vítima dessa opressão de gênero no meio social, a mulher brasileira também encontra dificuldade em denunciar ou buscar auxílio, pois essa mesma opressão é refletida nas instituições. Logo, 
A mulher teme, principalmente, não ser acreditada. Esse sentimento, aparentemente infundado, de fato se justifica. São incontáveis os relatos de discriminação, preconceito, humilhação e abuso de poder em relação às mulheres em situação de violência sexual. (DREZZET, 2003, p. 37)

Deste modo, chega-se à variável inicialmente destacada no estudo: a vergonha como fator de análise nas denúncias de crimes sexuais, o qual será demonstrado na próxima seção, destacando-se dados de pesquisas sobre a percepção da população brasileira sobre estes crimes. Nesta análise, buscou-se evidenciar como a vergonha e a má-reputação são elementos recorrentes e determinantes para que o relato das vítimas seja desvalorizado pelas instituições.

\section{O DESCRÉDITO DA NARRATIVA DA VÍTIMA NAS DENÚNCIAS DE CRIMES SEXUAIS NO BRASIL}

Considerando todos os apontamentos feitos, dando destaque às construções sociais relacionadas aos papéis de gênero na realidade brasileira, vê-se que as vítimas também estão sujeitas a dificuldades nos ambientes institucionalizados. Desta forma, ao buscar a prestação jurisdicional e o auxílio de órgãos públicos especializados, a vítima é novamente julgada e estigmatizada por seu comportamento e, assim, a vergonha passa a ser uma consequência direta deste julgamento.

Este é um fato essencial no contexto de crimes sexuais e na culpabilização incutida à vítima no Brasil, pois está diretamente relacionada aos índices de denúncias e repercussão do machismo na sociedade, o qual ocorre de uma forma estrutural e institucionalizada. Quanto ao primeiro fator, uma Nota Técnica divulgada pelo Ipea em 2014, a partir da coleta de dados do Sistema de Informações de Agravos de Notificação (Sinan), destacou que aproximadamente 527 mil pessoas são estupradas no país, sendo que $89 \%$ das vítimas são mulheres e apenas $10 \%$ de todos os casos são comunicados à polícia, pois

No Brasil, a maior parte das mulheres não registra queixa por constrangimento e humilhação, ou por medo da reação de seus conhecidos e autoridades. Também é comum que o agressor ameace 
a mulher de nova violência caso ela revele a que sofreu. (DREZZET et al, 1998, p. 29)

Ainda, sabendo que os principais agressores são pessoas próximas da vítima, principalmente seus companheiros/cônjuges ${ }^{2}$ e que a casa da vítima é o principal local de agressão, há um discurso no âmbito do direito processual penal de que a palavra da vítima deve ser revestida de maior peso no momento da apuração do fato criminoso. No entanto, devido a toda a sistemática patriarcal e machista presente na sociedade e também nas instituições, a palavra da vítima na verdade é totalmente desacreditada. Nesse sentido,

As pessoas ainda resistem a acreditar. "Mas, será?" Ficam buscando justificativa para aquele ato, ao invés de se apoiar na veracidade da palavra da vítima. "Será que não brigaram?"; "será que não há um interesse econômico aí?"; "ela está querendo se separar, será que ela não quer a guarda dos filhos e por isso ela está buscando esse argumento?". Então, transformam essa vítima em mentirosa, interesseira ou louca. É um exercício muito automático de descrédito da palavra da mulher, por parte da sociedade e da justiça, quando não se quer acreditar que aquele "pai de família" praticou um estupro. (AGÊNCIA, 2015)

E, ainda, como destacado pela professora Janaína Matida durante uma entrevista concedida à BBC em 2020, a ideia de que a palavra da vítima tem maior relevância nos casos de crimes sexuais leva a crer que mulheres estão protegidas de crimes sexuais, mas na realidade ocorre o inverso, pois são recebidas como mentirosas, sendo afastadas da qualidade de vítimas (ARANHA; MOTA, 2020). Ainda, neste mesmo estudo, a professora destaca que há muitas teses de defesas apresentadas no âmbito judicial em que a postura da mulher é considerada um fator determinante para o cometimento do crime, como por exemplo o seu comportamento sexual, o tipo de roupa que vestia na ocasião e até mesmo o horário em que estava fora de casa (ARANHA; MOTA, 2020).

Todos esses questionamentos põem em dúvida a palavra da vítima ao relatar os abusos sofridos. Ainda, mesmo que a vítima decida denunciar, estará diante de

\footnotetext{
${ }^{2}$ Os dados coletados pelo Ipea (2014) também revelam que 70\% dos crimes de estupro são cometidos por parentes, namorados, amigos ou conhecidos da vítima;
} 
abusos e humilhações, as quais são decorrentes do reflexo que as estruturas de poder presentes no âmbito social acarretam nas instituições, já que também repetem os papéis de gênero que são esperados de homens e mulheres. Assim, as denúncias de mulheres vítimas de crimes sexuais esbarram, como consequência, em outro problema: o fato de as instituições não estarem preparadas para lidar com essas demandas. Com isso, é mais do que compreensível o fato de que poucas mulheres denunciam os abusos sofridos, já que a sociedade e as instituições, em sua maioria, culpam a conduta da vítima e desacreditam em sua palavra, seus relatos e, indiretamente, acarretam na defesa do agressor e perpetuação de discursos machistas.

Assim, evidencia-se que, para encontrar possíveis soluções para crimes sexuais cometidos contra mulheres no Brasil, deve-se necessariamente haver a adoção de uma perspectiva feminista no processo de enfrentamento, já que tanto os preconceitos repassados no meio social, tanto a forma como as instituições se organizam são fatores determinantes para que a vítima seja reiteradamente responsabilizada. Neste sentido, a professora Janaína Matida também destaca a necessidade de pensar em mecanismos capazes de neutralizar o machismo no âmbito processual e investigatório, pois há um grande perigo de que esse pensamento seja utilizado como fundamento para o desfecho do caso (ARANHA; MOTA, 2020). Dentre esses machismos bastantes presentes no meio social, ressalta-se que a sexualidade feminina, quando exercida livremente - ou seja, fora dos padrões comportamentais esperados pela sociedade - é lida como uma má-reputação e até mesmo prova de culpa da vítima, assim como ocorreu durante a caça às bruxas.

Deste modo, passa a ser essencial que a vertente de enfrentamento, além de feminista, seja interseccional, uma vez que os dados evidenciam que a violência sexual, mesmo atingindo vários grupos de mulheres, vitimiza, em sua maioria, mulheres negras e jovens. Portanto, essa análise carece de uma perspectiva que esteja alinhada aos recortes de classe, raça e geração, como será demonstrado na próxima seção. 


\section{A NECESSIDADE DE UM ENFRENTAMENTO INSTITUCIONAL A PARTIR DE UMA PERSPECTIVA FEMINISTA INTERSECCIONAL}

Os principais dados estatísticos referentes a crimes sexuais no Brasil destacam que além de ser um problema generalizado que atinge variados grupos de mulheres, também vitimiza com mais abrangência mulheres negras e jovens. Como destacado pela pesquisa "A violência contra a mulher", publicada em 2016 pelo Ipea, ao dimensionar os dados referentes à ocorrência de violência sexual entre as entrevistadas, foi apurado que

Observando-se a incidência dessa violência tendo em conta a raça/cor e a faixa etária, nota-se que as mulheres negras são mais vulneráveis que as mulheres brancas, dado que $4,01 \%$ das mulheres negras afirmaram já terem sofrido alguma ofensa sexual ao longo da vida e $3,62 \%$ das mulheres brancas o disseram. É relevante a maior incidência dessa violência entre mulheres jovens, sendo que $1,2 \%$ das mulheres de 16 a 24 anos entrevistadas tinham sofrido alguma ofensa sexual nos doze meses anteriores à pesquisa. (Ipea, 2016, p. 23)

A leitura desses dados requer uma análise sobre o seu significado no contexto social no Brasil, principalmente no que se refere ao fator geracional. Neste sentido, destaca-se que há dados ainda mais alarmantes que evidenciam que esse tipo de violência também é bastante presente em grupos vulneráveis, como crianças e adolescentes $^{3}$. No entanto, ao ser cometido contra esses sujeitos, este delito se reveste de características e preocupações diversas das peculiaridades observadas quando jovens mulheres são vítimas, sendo elas o foco de análise nesta seção.

Assim, ao analisar os dados coletados tendo como eixo a predominância do cometimento de crimes sexuais contra mulheres jovens entre 16 e 34 anos - faixa etária delimitada pelo Ipea (2016) - o recorte geracional se torna um fator essencial para o estudo. Isso porque a insistência no cometimento de crimes sexuais contra mulheres jovens escancara o fato de serem violências reiteradas, já que são sofridas na própria casa, no trabalho, no transporte público, dentre outros espaços sociais. Tal

3 Os dados coletados pelo Sinan (Sistema de Informação de Agravos de Notificação), em 2013, revelaram que $60,5 \%$ das vítimas de crimes sexuais eram menores de 14 anos; 
afirmação é resultado de pesquisas sobre a percepção da população brasileira sobre o que é considerado "crime sexual", na qual foram apontadas práticas desde ouvir comentários ou cantadas que gerem medo, ter fotos ou vídeos íntimos divulgados sem autorização, até alcançar atos sexuais não consentidos, seja este cometido em um relacionamento ou não (INSTITUTO, 2016).

Ainda, considerando os fatores interseccionais relacionados às vítimas, a raça é lida como um fator determinante, já que houve no Brasil um processo histórico de hipersexualização dos corpos negros. Nesse sentido, destaca-se que o corpo feminino negro no Brasil foi social e midiamente construído pelo mito da "mulata fogosa", sendo um resultado do processo de miscigenação do período colonial. Deste modo, criou-se "a imagem da mulata: uma mulher sexualmente muito liberada, 'quente' e 'fogosa', o resultado da miscigenação de um homem branco com uma mulher negra" (HEILBORN, 2006, p. 49).

Para uma análise mais aprofundada sobre o tema, destacam-se trechos do estudo produzido por Fabiana Leonel de Castro, denominado "Negras jovens e feministas: sexualidade, imagens e vivências" ${ }^{4}$, no qual a autora evidencia como as mulheres negras foram descritas pelo imaginário social, destacando entre os fatores determinantes para tanto a hipersexualização do corpo negro feminino no Brasil. Neste sentido, a autora ressalta que a construção do imaginário da "mulata fogosa" foi elaborado e ainda é repassado como uma forma de poder, "que faz com que se atue de forma mais incisiva sobre alguns grupos" (CASTRO, 2010, p. 27), ou seja: sobre o corpo feminino negro. Assim, citando Sueli Carneiro (2005), Fabiana Leonel (CASTRO, 2010) também destaca que há relação direta entre sexualidade e racialidade, principalmente no contexto brasileiro, já que foi fundamentado em preceitos escravistas e patriarcais.

Deste modo, "a desdenhada imagem da mulata, síntese da mulher irresistivelmente sedutora e moralmente depravada" (STOLKE, 2006, p. 38) que tirou dos homens brancos a sua responsabilidade dos crimes sexuais cometidos no período

\footnotetext{
${ }^{4}$ Dissertação apresentada em 2010 como um dos requisitos para obtenção do grau de Mestre no Programa de Pós-Graduação em Estudos Interdisciplinares sobre Mulheres, Gênero e Feminismo da Universidade Federal da Bahia (UFBA);
} 
escravista, é refletida atualmente na forma com que as mulheres são responsabilizadas pelas violações, devido a este mito da "mulher fogosa" ainda se fazer presente na sociedade atual. Assim, mas não com a mesma predominância com que esse poder é exercido sobre os corpos negros, as mulheres, em geral, que exercem livremente sua sexualidade também são condenadas pelo seu comportamento, já que (no imaginário social) seduziram, excitaram, instigaram ou motivaram homens a uma prática sexual. Logo, atualmente, esse imaginário também retira dos homens brancos a sua responsabilidade sobre os crimes sexuais cometidos contra mulheres.

Evidenciando essa análise no atual contexto social, tem-se que: $42 \%$ dos homens defendem que crimes sexuais ocorrem porque a mulher provoca; que bebidas, drogas e problemas mentais são motivos para que violência sexual seja cometida contra mulheres; que $20 \%$ dos homens não acham que transar com namorada ou colega se ela estiver muito bêbada seja crime; que $24 \%$ concordam que sexo é parte do casamento, independente da vontade da mulher; e que $52 \%$ consideram que nada acontece quando um homem pratica violência sexual contra uma mulher (INSTITUTO, 2016). Esses dados corroboram com o posicionamento de que a mulher brasileira é constantemente responsabilizada por crimes sexuais, mesmo sendo vítima. Ainda, as estatísticas também evidenciam que a sexualidade feminina, quando exercida livremente e fora dos padrões de gênero esperados pela sociedade brasileira, é considerada uma prova de culpa e má-reputação para as mulheres. Com isso, as mulheres que ousam ser sexualmente livres no Brasil são taxadas como vadias, promíscuas e, como consequência, estão sujeitas a serem violadas em suas próprias casas e nos espaços públicos, sem que seus agressores sejam responsabilizados, já que as instituições também as julgam. Por isso, entendese que pensar em uma possível solução para o problema - ou ao menos formas de minimizá-lo - necessariamente requer a adoção de uma postura feminista interseccional e institucionalizada.

A motivação por uma luta feminista e interseccional é evidente ao se destacar a abrangência com que os crimes sexuais atingem mulheres no Brasil, considerando que mulheres negras jovens são as principais vítimas. Ainda, fala-se também em 
institucionalizada, pois de nada adianta mobilizações no campo social, se as instituições continuam perpetuando as dominações de gênero que também são verificadas no ambiente social. Neste sentido,

quando as leis não preveem que as vítimas da discriminação racial podem ser mulheres e que as vítimas da discriminação de gênero podem ser mulheres negras, elas acabam não surtindo o efeito desejado e as mulheres ficam desprotegidas. (CRENSHAW, 2004, p. 8-9)

Ademais, importante destacar que, em razão de toda a desigualdade social e de condições que estiveram presentes no processo de formação do país, os cargos de poder das instituições são majoritariamente ocupados por homens integrantes de um grupo hegemônico. Deste modo, a mulher vítima de crimes sexuais que busca amparo e uma resposta institucional, encontrará homens nos cargos de poder, os quais não são vítimas das opressões e dominações de gênero que estão impostas no meio social e, por isso, não reconhecem as peculiaridades que estão presentes nas dominações pautadas em gênero. Isso porque

Não é apenas a ação discriminatória, mas também a inação do Estado que dá livre curso às formas múltiplas de violência estrutural. A recusa dos direitos sexuais, a homofobia e o sexismo são vividos em sua conjugação com as desigualdades socioeconômicas e regionais, o racismo, aspectos geracionais e deficiências, entre outros fatores. (BIROLI, 2018, p. 82)

Neste sentido, defende-se a capacitação e formulação de procedimentos que levem em conta as peculiaridades em que os crimes sexuais são cometidos - dentro da casa da vítima, no ambiente de trabalho, no espaço público - ocasiões em que estruturas de poder pautadas em gênero naturalmente se repetem: homem/mulher, marido/esposa, pai/filha, irmão/irmã, patrão/empregada, etc. Logo, se as opressões partem de fatores interseccionais, sendo o gênero e raça questões preponderantes, necessariamente a reivindicação de mudança e luta por direitos sexuais também deve abarcar essa perspectiva. 


\section{CONCLUSÃO}

Conforme dito, aspectos subjetivos dos indivíduos agregam construções sociais de acordo com a realidade em que se inserem e, dentre estes, a sexualidade. Neste processo de agregação, outros fatores também passam a ser determinantes para a forma com que esses aspectos serão lidos, entre os quais destacamos no estudo raça, geração e, principalmente, o gênero. Pelo próprio conceito que pressupõe, o fator gênero cria diferentes experiências para homens e mulheres, sendo que para estas predominam fatores negativos. Deste modo, baseando-se em questões de gênero, são incutidas às mulheres obrigações, limitações e violências. Deste modo, mulheres não usufruem livremente da liberdade sexual da mesma forma que os homens, já que são estigmatizadas pelos seus comportamentos. Ainda, os homens não sofrem com as violências do mesmo modo que as mulheres, já que o corpo masculino, em sua maioria, não é lido como o feminino.

Assim, crimes sexuais cometidos contra mulheres necessariamente perpassam por fatores de gênero, já que é a essência dos paradoxos entre homens e mulheres, inclusive o de agressor e vítima. Ademais, na realidade brasileira, raça e geração não passam despercebidos, conforme destacado ao longo do estudo. O encontro de todos esses fatores resulta na culpabilização da vítima, a qual é historicamente julgada e desacreditada. Deste modo, a mulher brasileira está sujeita também a uma violência institucional, já que até mesmo em órgãos públicos as violências de gênero são refletidas. Como consequência, a mulher é retirada da qualidade de vítima e passa a ser vista como a responsável pelo delito, razão pela qual não é mais tutelada pelo Estado, mas sim responsabilizada, pois não the é permitido o exercício livre da sexualidade.

Deste modo, compreende-se que as mulheres que exercem livremente a sua sexualidade no contexto brasileiro não estão apenas buscando prazer ou amor, mas sim a reivindicação de direitos que necessariamente recai na luta por igualdade entre homens e mulheres. Desta forma, "se ser livre é ser vadia, somos todas vadias" (VELOSO, 2016, p. 33), já que a liberdade sexual é um direito que deve ser reconhecido e garantido, enquanto um fator inerente a todos os sujeitos e corpos. 


\section{REFERÊNCIAS}

AGÊNCIA PATRícIA GALVÃO. Estupro. São Paulo: Agência Patrícia Galvão, 2015. Disponível em: https://dossies.agenciapatriciagalvao.org.br/violencia-sexual/tipos-deviolencia/estupro/. Acesso em: 16 nov. 2020.

AGÊNCIA PATRÍCIA GALVÃO. Violência Sexual. São Paulo: Agência Patrícia Galvão, 2015. Disponível em:

https://dossies.agenciapatriciagalvao.org.br/violencia/violencias/violencia-sexual/. Acesso em: 16 nov. 2020.

BIROLI, Flávia. Gênero e Desigualdades: os limites da democracia no Brasil. São Paulo: Boitempo, 2018.

CARNEIRO, Sueli. A construção do outro como não-ser como fundamento do ser. 2005. 339f. Tese (Doutorado) - Universidade de São Paulo, São Paulo, 2005.

CASTRO, Fabiana Leonel de. Negras jovens feministas: sexualidade, imagens e vivências. 2011. 132fl. Dissertação (Mestrado) - Universidade Federal da Bahia, Salvador, 2010.

CONDREN, Mary. The Serpent and the Goddess: Women, Religion, and Power in Celtic Ireland. São Francisco: Harper \& Row, 1989.

CRENSHAW, Kimberlé. A interseccionalidade na discriminação de raça e gênero. IN: VV.AA. Cruzamento: raça e gênero. Brasília: Unifem, 2004. Disponível em: https://bit.ly/25YkehZ. Acesso em: 05 dez. de 2020.

DREZZET, Jefferson. Violência sexual contra a mulher e impacto sobre a saúde sexual e reprodutiva. São Paulo: Centro de Referência da Saúde da Mulher, 2003.

DREZETT, J., BALDACINI, I., FREITAS, G.C., PINOTTI, J.A. Contracepção de emergência para mulheres vítimas de estupro. Revista do Centro de Referência, n³, p. 29-33, 1998.

FEDERICI, Silvia. Calibã e a bruxa: mulheres, corpo e acumulação primitiva. São Paulo: Editora Elefante, 2017.

FOUCAULT, Michel. História da Sexualidade I: A Vontade de Saber. Rio de Janeiro, Edições Graal, 1977.

HEILBORN, Maria Luiza. Experiência da Sexualidade, Reprodução e Trajetórias Biográficas Juvenis: o olhar das ciências sociais. In.: HEILBORN, Maria Luiza et all (Org.). O Aprendizado da Sexualidade: Reprodução e trajetória sociais de jovens brasileiros. Rio de Janeiro: Gramond e Fiocruz, 2006. p. 29-57. 
IPEA - INSTITUTO DE PESQUISA ECONÔMICA APLICADA. A violência contra a mulher. Brasília: Ipea, 2016.

INSTITUTO PATRÍCIA GALVÃO. Pesquisa Violência Sexual: percepções e comportamentos sobre violência sexual no Brasil. São Paulo: Agência Patrícia Galvão, 2016.

ARANHA, Estela; MOTA, Janaína Matida. De Angela Diniz a Mariana Ferrer, como a Justiça põe mulheres no "banco dos réus" em casos de violênica. [Entrevista concedida a] MOTA, Camila Veras; IDOETA, Paula Adamo. BBC News. São Paulo, 5 nov. 2020. Disponível em: https://www.bbc.com/portuguese/brasil-54826363.amp. Acesso em: 16 nov. 2020.

SCOTT, Joan. Gênero: uma categoria útil de análise histórica; tradução Guacira Lopes Louro. Paris: Editions Tierce, 1988.

STOLKE, Verena. O enigma das interseções: classe, "raça", sexo, sexualidade: a formação dos impérios transatlânticos do século XVI ao XIX. Revista Estudos Feministas, vol.14, no.1. Florianópolis: UFSC, 2006. p. 15-42.

VELOSO, Cyrana Borges. "Se ser livre é ser vadia, somos todas vadias?": a marcha das vadias e os movimentos feministas brasileiros. Em Debate: Periódico de Opinião Pública e Conjuntura Política, Belo Horizonte, ano 8, n. 5, p. 33-41, jul. 2016. 